\title{
Endodontic photoactivated disinfection using a conventional light source: an in vitro and ex vivo study
}

\author{
Sebastian Schlafer, DDS, ${ }^{\text {a }}$ Michael Vaeth, ${ }^{\mathrm{b}}$ Preben Hørsted-Bindslev, DDS, ${ }^{\mathrm{c}}$ \\ and Ellen V. G. Frandsen, DrOdont, ${ }^{\mathrm{d}}$ Aarhus, Denmark \\ FACULTY OF HEALTH SCIENCES, AARHUS UNIVERSITY
}

\begin{abstract}
Objective. The antimicrobial effect of photoactivated disinfection (PAD) using toluidine blue and an LED lamp was tested on endodontic pathogens in planktonic suspension and after inoculation into extracted teeth. Irradiation time was limited to 30 seconds.

Study design. The effect of PAD on planktonic suspensions of Escherichia coli, Candida albicans, Enterococcus faecalis, Fusobacterium nucleatum, and Streptococcus intermedius was analyzed using Poisson regression. Moreover, cultures of $S$. intermedius were inoculated into prepared root canals of extracted molars. The effect of PAD performed immediately after inoculation or after overnight bacterial incubation was determined by a 2-sample $t$ test.
\end{abstract}

Results. Photoactivated disinfection yielded significant reductions $(P<.001)$ in the viable counts of all organisms in planktonic suspension. The PAD treatment of $S$. intermedius in root canals yielded a mean $\log 10$ reduction of 2.60 $(P<.001)$ immediately after inoculation and of $1.38(P<.001)$ after overnight incubation.

Conclusion. Photoactivated disinfection using a conventional light source strongly reduces the number of viable endodontic pathogens in planktonic suspension and in root canals. (Oral Surg Oral Med Oral Pathol Oral Radiol Endod 2010;109:634-641)

Failure in endodontic treatment is common. While success rates of $85 \%$ and above have been shown in controlled clinical studies, ${ }^{1-3}$ the majority of crosssectional studies reveals a different picture. In a considerable number of investigations from different countries, periapical radiolucencies were prevalent in $35-65 \%$ of all root canal treated teeth. ${ }^{4-9}$ Given the relatively low sensitivity of radiographic assessment for early diagnosis of periapical inflammation, ${ }^{10,11}$ these numbers might even underestimate the true frequency of endodontic failure.

Among the reasons accounting for unsuccessful treatment, insufficient removal of the microorganisms infecting the root canal system plays an important role. The intricate dental anatomy strongly limits the effect of mechanical debridement. Even thorough preparation of the root canal using either conventional hand files or nickel-titanium rotary files does not permit full removal of the contaminated innermost layer of dentin. ${ }^{12,13}$ Moreover, lateral canals and apical ramifications are

\footnotetext{
Supported in part by CMS Dental, Copenhagen.

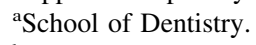

bProfessor, Department of Biostatistics, Institute of Public Health.

${ }^{\mathrm{c}} \mathrm{School}$ of Dentistry.

${ }^{\mathrm{d} S}$ School of Dentistry.

Received for publication Oct 4, 2009; accepted for publication Dec 13, 2009.

$1079-2104 / \$$ - see front matter

(C) 2010 Mosby, Inc. All rights reserved.

doi:10.1016/j.tripleo.2009.12.027
}

inaccessible to root canal instruments. Methods of chemical disinfection supporting the instrumental endodontic debridement have a strong bactericidal effect, but commonly used irrigants, such as sodium hypochlorite $(\mathrm{NaOCl})$ and chlorhexidine digluconate, and calcium hydroxide as an interappointment dressing do not always eradicate the entire microbial flora in infected root canals. ${ }^{14-16}$ Endodontic pathogens have developed a variety of strategies to survive in adverse conditions. They may invade dentinal tubules and persist in superficial layers of dentin adjacent to the canal lumen, ${ }^{17,18}$ and they may organize as biofilms, complex sessile communities performing numerous adaptive changes in behavior that increase their resistance to a variety of chemotherapeutic agents compared with their planktonic counterparts. ${ }^{19}$ Because the persistence of cultivable microbes at the time of obturation is clearly related to treatment failure, ${ }^{20,21}$ there is a strong need to improve the efficacy of disinfecting procedures in endodontic therapy.

Photoactivated disinfection (PAD) has been proposed as an adjunct to conventional endodontic treatment. Light of an appropriate wavelength activates a photosensitizing molecule attached to the bacterial/fungal membrane and eventually leads to production of highly reactive oxygen species able to kill microorganisms. In a number of studies the successful use of laser light in combination with photosensitizers has been reported. $^{22-32}$ However, to avoid heat damage in periapical tissues, ${ }^{33,34}$ the lasers used in those studies are all 
characterized by a very limited energy output. This renders the PAD procedure rather time consuming, with irradiation times between 2.5 and 10 minutes for a single canal. Moreover, the high cost of laser devices makes them unaffordable for most clinicians and hampers their widespread use.

Conventional light sources might be a solution. They are reasonably priced alternatives and induce safer temperature increases when applied on enamel or dentin. ${ }^{35,36}$ Although they have not, to our knowledge, been used in endodontic therapy, they have been applied successfully to treat a variety of infections in the field of dermatology. ${ }^{37,38}$ Moreover, a PAD study comparing the effect of a laser and a conventional light source on periodontal pathogens reported promising results for the use of noncollimated light on oral bacteria. ${ }^{39}$ In the present study, a light-emitting diode (LED) lamp emitting light in the red spectrum was used throughout the experiments to investigate the effect of PAD on endodontic pathogens in both planktonic suspension and in root canals of extracted human molars.

\section{MATERIALS AND METHODS}

\section{Microorganisms}

The organisms Escherichia coli (NCO 09001; National Collection of Type Cultures [NCTC], London, U.K.; =ATCC $11775^{\mathrm{T}}$ ), Candida albicans (NCPF 3179; NCTC; =ATCC 10231), Fusobacterium nucleatum (NCO 10562; NCTC; =ATCC 10953), Enterococcus faecalis (CCUG 19916; Culture Collection of the University of Gothenburg, Sweden), and Streptococcus intermedius (SK 54; M. Kilian, University of Aarhus, Denmark; =ATCC $27335^{\mathrm{T}}$ ) were used in the experiments. Escherichia coli, Enterococcus faecalis and $S$. intermedius were cultivated on blood agar, and $F$. nucleatum was grown on modified Columbia blood agar. $^{40}$ All bacteria were cultivated anaerobically at $37^{\circ} \mathrm{C}$. Candida albicans was grown on Sabouraud agar and incubated at $37^{\circ} \mathrm{C}$ in air enriched with $5 \% \mathrm{CO}_{2}$. Experiments involving bacteria were performed with overnight liquid cultures in plaque medium. Plaque medium contains $10 \mathrm{~g}$ tryptone peptone (Difco, West Molesey, U.K.), $10 \mathrm{~g}$ yeast extract (Difco), $2.5 \mathrm{~g}$ $\mathrm{K}_{2} \mathrm{HPO}_{4}, 2.5 \mathrm{~g} \mathrm{MgSO}_{4} \times 7 \mathrm{H}_{2} \mathrm{O}, 2 \mathrm{~g}$ starch, $2 \mathrm{~g}$ glucose, $1 \mathrm{~g}$ L-cysteiniumchlorid, and $1,000 \mathrm{~mL}$ distilled water, adjusted to $\mathrm{pH} 7 .^{41}$ After centrifugation at $3,000 \mathrm{rpm}$ for 5 minutes, the bacterial pellets were resuspended in $0.85 \%$ sterile saline and washed once. Suspensions of $S$. intermedius were then vortexed vigorously with sterilized glass beads $(100 \mu \mathrm{m})$ for 2 minutes to disrupt bacterial aggregates. For overnight infection of extracted teeth, cultures of $S$. intermedius in plaque medium were used directly. Candida albicans was directly transfered from the agar to $0.85 \%$ sterile saline. After calibration to cell counts in a light microscope counting chamber, a spectrophotometer (Shimadzu, Kyoto, Japan) was used at a wavelength of 550 $\mathrm{nm}$ to adjust the concentration of microorganisms to $10^{7}-10^{8} / \mathrm{mL}$ for all experiments (Table I).

\section{Light source and photosensitizer}

An LED lamp emitting in the red spectrum with a power peak at $628 \mathrm{~nm}$ was the light source used throughout all of the experiments (FotoSan; CMS Dental, Copenhagen, Denmark). The relative spectral power distribution is shown in Fig. 1. The energy output was measured to be $1 \mathrm{~J} / \mathrm{s}$. The light was guided in 2 different ways according to the experimental setup. For PAD of microorganisms in planktonic suspension, the lamp was provided with a short coned conductive tip of $4 \mathrm{~mm}$ diameter at the cone end. It is referred to as the planktonic tip. For PAD experiments on extracted teeth, a longer tapered tip, referred to as the endodontic tip, was mounted (Fig. 2). With its apical size of $500 \mu \mathrm{m}$ and a 0.03 taper in the apical part it could be inserted into the canals up to 3 $\mathrm{mm}$ short of the working length and guide the light to the apical parts.

A watery solution of toluidine blue O (TBO; Sigma-Aldrich, St. Louis, MO), a thiazine dye of the quinone-imine family, was prepared to concentrations varying between $10 \mu \mathrm{g} / \mathrm{mL}$ and $100 \mu \mathrm{g} / \mathrm{mL}$ and stored in the dark at $4^{\circ} \mathrm{C}$ until used as photosensitizer in the experiments.

\section{PAD treatment of microorganisms in planktonic suspension}

In a first part, all 5 organisms were subjected to PAD treatment: $100 \mu \mathrm{L}$ TBO solution in a concentration of $100 \mu \mathrm{g} / \mathrm{mL}$ and an equal volume of bacterial/fungal suspension were injected into the lid of a sterile $1.5 \mathrm{~mL}$ Eppendorf tube and carefully mixed with a sterile pipette tip. One minute after the application of TBO, the planktonic tip was inserted into the suspension and irradiation was performed for 30 seconds. The negative control treatment was carried out by mixing $100 \mu \mathrm{L}$ microbial suspension with an equal volume of $0.85 \%$ sterile saline instead of TBO solution. One minute after mixing, the planktonic tip was inserted for 30 seconds, but the sample was not irradiated. To analyze the effect of TBO alone, equal volumes of microbial suspension and TBO solution were mixed, and the pulp chamber tip was inserted for 30 seconds without irradiating the sample. To analyze a potential effect of the light alone, equal volumes of bacterial/fungal suspension and sterile saline were mixed and subjected to 30 seconds of irradiation. For each of the 5 organisms, the microbial suspension for all 4 setups was taken from the same parent suspension. Immediately after treatment, an ali- 

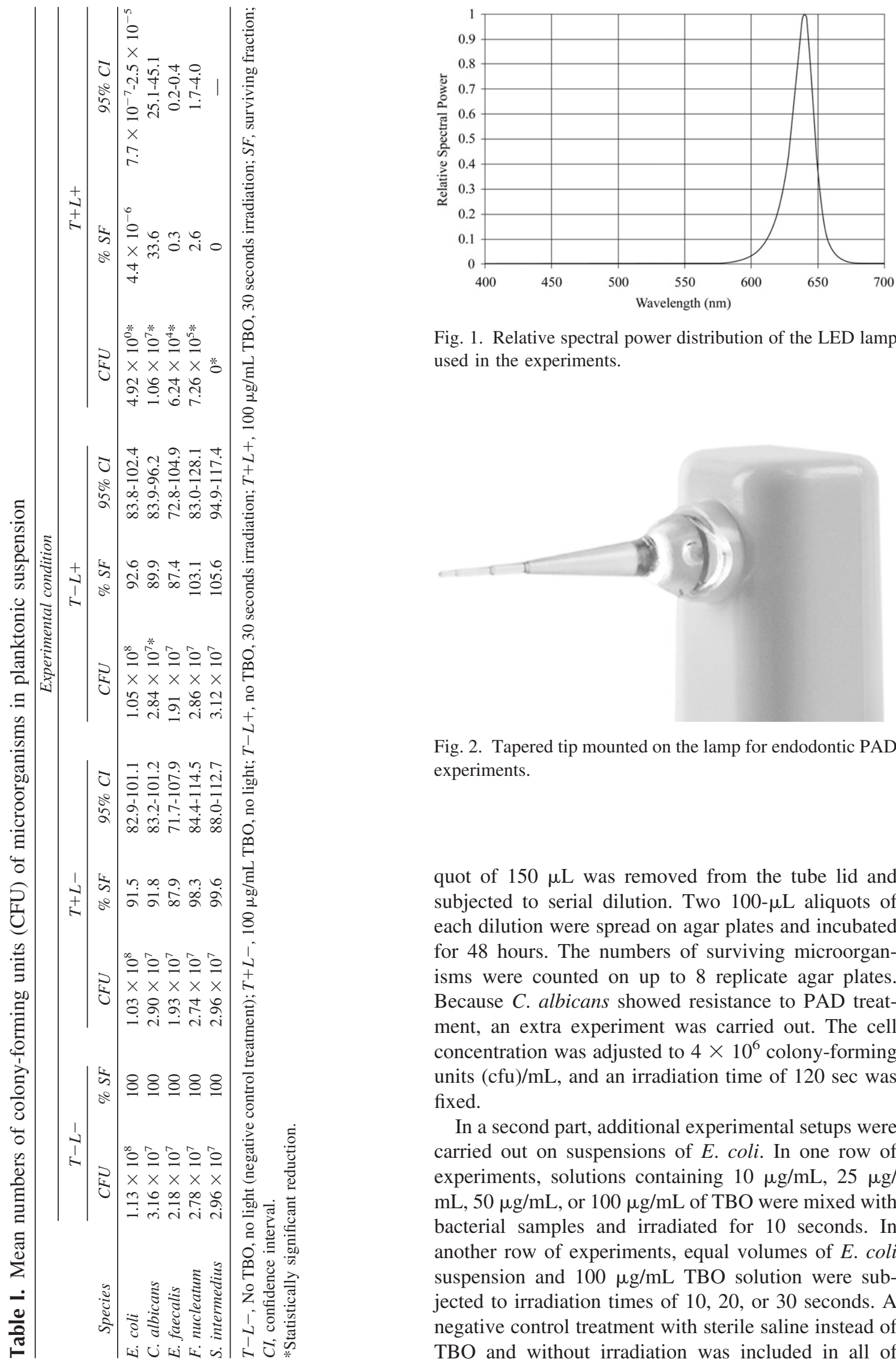

Fig. 1. Relative spectral power distribution of the LED lamp used in the experiments.

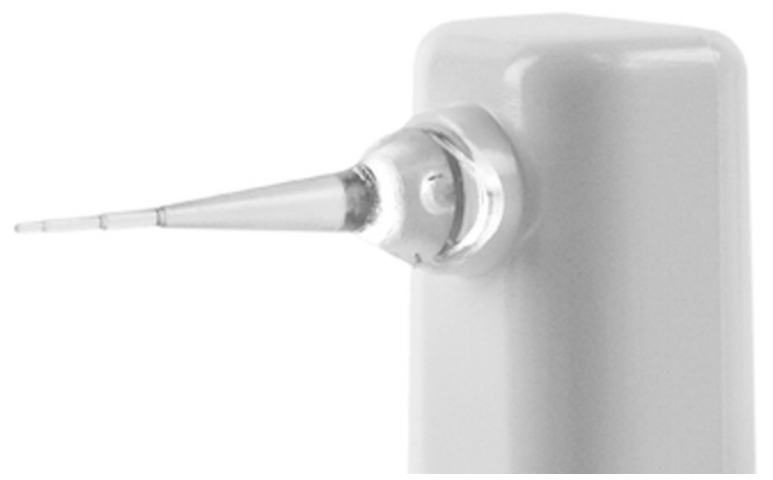

Fig. 2. Tapered tip mounted on the lamp for endodontic PAD experiments.

quot of $150 \mu \mathrm{L}$ was removed from the tube lid and subjected to serial dilution. Two $100-\mu \mathrm{L}$ aliquots of each dilution were spread on agar plates and incubated for 48 hours. The numbers of surviving microorganisms were counted on up to 8 replicate agar plates. Because $C$. albicans showed resistance to PAD treatment, an extra experiment was carried out. The cell concentration was adjusted to $4 \times 10^{6}$ colony-forming units $(\mathrm{cfu}) / \mathrm{mL}$, and an irradiation time of $120 \mathrm{sec}$ was fixed.

In a second part, additional experimental setups were carried out on suspensions of $E$. coli. In one row of experiments, solutions containing $10 \mu \mathrm{g} / \mathrm{mL}, 25 \mu \mathrm{g} /$ $\mathrm{mL}, 50 \mu \mathrm{g} / \mathrm{mL}$, or $100 \mu \mathrm{g} / \mathrm{mL}$ of TBO were mixed with bacterial samples and irradiated for 10 seconds. In another row of experiments, equal volumes of $E$. coli suspension and $100 \mu \mathrm{g} / \mathrm{mL}$ TBO solution were subjected to irradiation times of 10,20 , or 30 seconds. A negative control treatment with sterile saline instead of TBO and without irradiation was included in all of 
these experiments. Again, all of the bacterial aliquots for 1 experimental series derived from 1 parent suspension. After treatment, dilution, plating, and counting were carried out as described above. All of the experiments carried out on microorganisms in planktonic suspension were repeated on another day.

\section{Processing of teeth for endodontic PAD treatment}

For endodontic experiments, 80 freshly extracted human molars, 40 of them deriving from the upper jaw, 40 from the lower jaw, were collected and stored in $70 \%$ ethanol. None of the teeth had undergone endodontic treatment before extraction. After removal of carious tooth substance, access to the pulp chambers was gained and the most curved root canal of each tooth was selected for treatment. Angulations between crowns and apical parts of the roots were measured according to the method of Schneider and ranged between $2^{\circ}$ and $63^{\circ} .{ }^{42}$ Canal preparation was performed using a sequence of rotary nickel-titanium files (ProTaper; Dentsply Maillefer, Ballaigues, Switzerland) achieving a final canal size of ISO 40 at the apical constriction. Between every 2 instrumentations, the canal was rinsed with copious volumes of $0.5 \% \mathrm{NaOCl}$ solution. After shaping of the most curved canal, the apex was sealed with glass ionomer cement (GcFuji II; GC Corporation, Tokyo, Japan), as were the orifices of the canals that were not subjected to preparation. Subsequently, the shaped canal was irrigated with $1 \mathrm{~mL}$ 17\% EDTA solution for 3 minutes to remove the smear layer, followed by $1 \mathrm{~mL} 6 \% \mathrm{NaOCl}$ solution for 3 minutes. The root surfaces of molars used for overnight bacterial incubation were sealed with 2 layers of nail polish to prevent leakage. All teeth were autoclaved at $121^{\circ} \mathrm{C}$ for 20 minutes and kept individually in $0.85 \%$ sterile saline until used. After the experiments, the teeth were again rinsed with EDTA and $\mathrm{NaOCl}$ solutions as described above, reautoclaved, and reused once.

\section{Endodontic PAD treatment}

Cultures of $S$. intermedius were used for all endodontic PAD experiments. Before inoculation of each tooth, the prepared canal and pulp chamber were dried carefully using sterile endodontic paper points (ISO 35; Coltène/Whaledent, Langenau, Germany).

Two series of experiments were performed. In the first series, PAD treatment was performed shortly after bacterial inoculation. Twenty teeth were subjected to PAD treatment, and 20 teeth received negative control treatment. The bacterial inocula for one PAD-treated tooth and the respective negative control tooth were taken from the same parent suspension.

PAD treatment procedure. A $75 \mu \mathrm{L}$ volume of bacterial suspension and an identical volume of TBO so- lution $(100 \mu \mathrm{g} / \mathrm{mL})$ were mixed for 10 seconds and injected into the canal with a sterile single-use endodontic syringe (VMK-Endoneedle; Vedefar, Dilbeek, Belgium). A sterile endodontic file (ISO 15, stainless steel; Kerr, Scafati, Italy) was inserted down to the working length and moved gently to eliminate potential air bubbles. Any excess of liquid in the pulp chamber was removed with a sterile pipette tip. Doing this, only the remainder of the suspension within the root canal was subjected to PAD and subsequent sampling. Sixty seconds after inoculation, the endodontic tip of the LED lamp was inserted into the canal and 30 seconds of irradiation treatment was performed. After removal of the endodontic tip, a sterile endodontic paper point (ISO 20; Coltène/Whaledent) was inserted and left in the canal for 15 seconds to absorb part of the residual volume. Subsequently, the point was transfered to $1 \mathrm{~mL}$ $0.85 \%$ sterile saline and vortexed vigorously for 1 minute. Then the paper point was removed, and serial dilution, plating in duplicate, and counting were performed as described for the planktonic experiments.

Negative control treatment procedure. In the negative control treatment, the bacterial suspension was mixed with an equal volume of $0.85 \%$ sterile saline instead of TBO before inoculation. The endotip was inserted into the canal, but no irradiation was performed. All other steps were carried out as for the PAD procedure. After treatment, all 40 teeth were resterilized as described above, and the 20 teeth that had undergone negative control treatment were now subjected to PAD treatment, and the teeth subjected to PAD treatment in the first part now received the negative control treatment, resulting in a total of $40 \mathrm{PAD}$ and 40 control treatments.

\section{Second series}

In the second series of experiments, treatment was performed after overnight bacterial incubation. All teeth were inoculated with $75 \mu \mathrm{L} S$. intermedius suspension. Gentle stirring was carried out with a sterile file (ISO 15). The teeth were incubated at $37^{\circ} \mathrm{C}$ under anaerobic conditions. Again, half of the teeth were submitted to PAD and the other half to the negative control treatment.

$P A D$ treatment procedure. Any remainder of the bacterial suspension was carefully absorbed with sterile paper points. A $75-\mu \mathrm{L}$ volume of TBO solution (100 $\mu \mathrm{g} / \mathrm{mL}$ ) was injected into the root canal. To promote penetration of the photosensitizer into the canal wall, 30 seconds of circumferential filing with a sterile endodontic file (ISO 35, stainless steel; Kerr) was performed. The endodontic tip was inserted, and $30 \mathrm{sec}-$ onds of irradiation followed. The tip was removed, and the content of the canal was carefully dried using sterile 
paper points. Subsequently, $15 \mu \mathrm{L} 0.85 \%$ sterile saline was injected into the canal and another 30 seconds of circumferential filing with a sterile endodontic file (ISO 35) was carried out. Two sterile paper points (ISO 20) were inserted to absorb part of the resulting bacterial suspension, and they were transfered to $1 \mathrm{~mL} 0.85$ sterile saline along with the endodontic file and vortexed vigorously for 1 minute. Subsequently, file and paper points were removed and serial dilution, plating, and counting were performed.

Negative control treatment procedure. Instead of TBO, $75 \mu \mathrm{L}$ sterile saline was injected into the canals. The endodontic tips were inserted, but no irradiation was executed. All other steps were performed as in the PAD procedure. After treatment, the molars were disinfected, sterilized, and submitted to the opposite treatment as described above, yielding a total of 20 PAD and 20 control treatments.

To exclude contamination, 1 additional sterile control tooth was included in each of the endodontic PAD experiments. Instead of the bacterial suspension, $75 \mu \mathrm{L}$ $0.85 \%$ sterile saline was injected into the canal. All other steps were performed as in the negative control treatment.

\section{Statistical analysis}

Poisson regressions were used to analyze the data from the experiments performed on microorganisms in planktonic suspension, assuming that the random variation of the counts could be described by a Poisson distribution, with the mean being inversely proportional to the dilution factor. Each organism was considered separately. Robust standard errors were calculated to account for a possible overdispersion. The results of each treatment were expressed as the survival rate relative to the negative control treatment $(\mathrm{T}-\mathrm{L}-$, sterile saline instead of TBO, no irradiation). The survival rate was estimated as the ratio of mean counts for a given dilution.

The experiments involving teeth were designed as 2-period cross-over studies with 2 treatment groups (PAD treatment and negative control treatment). One group of teeth received the PAD treatment first and then the negative control treatment. The other group received identical treatments, but in reverse order. For each period the data from a tooth were summarized as a mean surviving count adjusted for the dilution factors that were used. An analysis of a cross-over design was then applied to the logarithm of these counts. In this analysis, the hypothesis of identical survival was assessed by a comparison of the differences between the log-counts in the first and second period using a 2-sample $t$ test. The logarithm of the survival rate was estimated as half the difference between the mean difference in each group.

A 5\% level of significance was used when assessing the result of a statistical test. Estimates are presented with a $95 \%$ confidence interval (CI). Stata $10^{43}$ was used for the statistical analyses.

\section{RESULTS}

\section{PAD treatment of microorganisms in planktonic suspension}

The numbers of $\mathrm{cfu} / \mathrm{mL}$ after negative control treatment (no irradiation, sterile saline instead of TBO) served as baseline for comparison throughout the study (Table 1). In the first part, application of $100 \mu \mathrm{g} / \mathrm{mL}$ TBO without irradiation resulted in mild reductions in the viable counts of all 5 organisms, none of which was statistically significant. Likewise, irradiation therapy without the photosensitizer did not achieve major killing rates for any of the organisms. However, the mean reduction of $10.1 \%\left(0.046 \log _{10}\right.$ reduction) of C. albicans cells by light alone was statistically significant $(P=.002)$. PAD treatment using TBO in a concentration of $100 \mu \mathrm{g} / \mathrm{mL}$ and performing 30 seconds of irradiation yielded highly significant reductions $(P<.001)$ in the viable counts of all organisms compared with the negative control treatment. However, susceptibility to PAD varied among the organisms. Complete or nearly complete eradication could be achieved for $S$. intermedius and E. coli, followed by E. faecalis with a mean killing rate of $99.7 \%$ (2.60 $\log _{10}$ reduction) and $F$. nucleatum with a mean killing rate of $97.4 \%\left(1.58 \log _{10}\right.$ reduction). Candida albicans proved to be the least sensitive of the examined organisms, showing a mean posttreatment survival rate of $33.6 \%\left(0.47 \log _{10}\right.$ reduction). Subjecting suspensions of C. albicans to 120 seconds of irradiation, a considerably lower survival rate of $0.003 \%$ o (95\% CI $0.00071 \%$ o-0.014\%o; $5.50 \log _{10}$ reduction) could be achieved compared with the negative control treatment. Comprehensive data are shown in Fig. 1.

In the second part, the effects of different concentrations of TBO were compared. Application of $10 \mu \mathrm{g} /$ $\mathrm{mL}, 25 \mu \mathrm{g} / \mathrm{mL}, 50 \mu \mathrm{g} / \mathrm{mL}$, and $100 \mu \mathrm{g} / \mathrm{mL}$ along with 10 seconds of irradiation resulted in mean E. coli survival rates of $0.067 \%$ o (95\% CI $0.024 \%$ o- $0.131 \%$; 4.18 $\log _{10}$ reduction), $0.055 \%$ (95\% CI $0.030 \%$ o $0.087 \%$; $4.26 \log _{10}$ reduction), $0.1 \%$ (95\% CI $0.052 \%$ - $0.194 \%$; $4.00 \log _{10}$ reduction), and $0.03 \%$ (95\% CI $0.016 \%$ $0.057 \%$; $4.52 \log _{10}$ reduction), respectively. Treatment with $100 \mu \mathrm{g} / \mathrm{mL}$ TBO proved to be significantly more effective than with the other concentrations used $(P<$ $.001)$. Furthermore, treatment effects using different irradiation times were compared. Ten seconds of light in combination with TBO in a concentration of 100 
$\mu \mathrm{g} / \mathrm{mL}$ resulted in a mean $E$. coli survival rate of $0.057 \%$ o (95\% CI 0.040\%o-0.082\%o; $4.24 \log _{10}$ reduction), and full kills were achieved by irradiation for 20 seconds and for 30 seconds. Based on these results, 30 seconds of light was chosen for the experiments involving teeth.

\section{Endodontic PAD treatment}

The absence of cultivable microorganisms in samples gained from sterile control teeth confirmed successful sterilization and contamination-free handling of the molars under the experiments. Performing PAD on cultures of $S$. intermedius immediately after inoculation of the teeth (30 s, $100 \mu \mathrm{g} / \mathrm{mL}$ TBO) yielded a mean survival rate of $0.25 \%$ (95\% CI $0.07 \%-0.94 \% ; 2.60$ $\log _{10}$ reduction) compared with the negative control treatment $(P<.001)$. The PAD treatment on teeth incubated overnight with $S$. intermedius had a lower, but still highly significant, effect $(P<.001)$. The mean survival rate was $4.18 \%$ (95\% CI 1.90\%-9.17\%; 1.38 $\log _{10}$ reduction).

\section{DISCUSSION}

The risk of injuring periapical tissues with heat generation imposes energy limitations on laser devices used for endodontic PAD. They usually operate at an output of $\leq 100 \mathrm{~mW} .{ }^{23}$ Consequently, effective killing of endodontic pathogens is a time-consuming procedure. The LED lamp used in the present study provides a considerably higher energy output, emitting $1 \mathrm{~J} / \mathrm{s}$. The temperature rise at the root surface was not measured in this study, but it is unlikely that any heat damage is done by the treatment, because the tooth and even the endotip may be held in the hand during the irradiation procedure without noticing any temperature change. The lamp was used for short irradiation periods of 30 seconds to investigate the effect of conventional-light PAD on microorganisms infecting root canals.

The first stage of the experiments focused on microbes in planktonic suspension. With E. faecalis and S. intermedius, 2 gram-positive facultative anaerobes were chosen for the study. In addition, $F$. nucleatum, a gram-negative obligate anaerobe, and C. albicans, a yeast, were selected. All of these 4 organisms have repeatedly been associated with primary and secondary endodontic infections using both advanced anaerobic culturing techniques and DNA-based methods. ${ }^{44-48}$ Finally, E. coli, a gramnegative facultative anaerobe, was included in the experiments. Within the limited irradiation time of 30 seconds, an overwhelming bactericidal effect could be observed on suspensions of $S$. intermedius and $E$. coli. Enterococcus faecalis and $F$. nucleatum showed a fair susceptibility to the treatment, whereas the mean $C$. albicans killing rate of $66.37 \%$ (0.47 $\log _{10}$ reduction) might not be considered to be satisfactory. Reasons may be found in the notable size of $C$. albicans cells, accounting for a high lethal dose of singlet oxygen. This line of thought is supported by the considerably higher mean killing rate of $99.9997 \%\left(5.50 \log _{10}\right.$ reduction) achieved in the additional Candida experiments using extended irradiation times of 120 seconds. Moreover, it could be demonstrated by Demidova and Hamblin $^{49}$ that the efficiency of PAD treatment on $C$. albicans strongly decreases as the concentration of cells in the irradiated suspension rises. Confronting the lamp with $3 \times 10^{7} \mathrm{cfu} / \mathrm{mL}$ certainly is a challenge and represents a high bacterial load compared with a typical in vivo situation. Part of the improved treatment outcome in the additional Candida experiments might be explained by the lower initial cell concentration of $4 \times$ $10^{6} \mathrm{cfu} / \mathrm{mL}$.

In the second stage of the study, PAD was performed on extracted molars. High susceptibility to PAD and ease of growth were the reasons to choose cultures of $S$. intermedius for these experiments. Because the planktonic part had not revealed a significant effect of either TBO or light alone, the only 2 setups carried out were the actual PAD treatment and the negative control treatment (no irradiation, sterile saline instead of TBO). A concentration of $100 \mu \mathrm{g} / \mathrm{mL}$ TBO was used in all experiments involving teeth, because the additional experiments on planktonic suspensions of $E$. coli had shown that $100 \mu \mathrm{g} / \mathrm{mL}$ yielded significantly higher killing rates than lower concentrations of TBO. Because the hardest task for practitioners is the endodontic treatment of molars, especially curved root canals,${ }^{50}$ the most curved roots of molars were chosen for preparation. Inoculating one tooth scheduled for PAD and the respective negative control tooth with the identical bacterial parent suspension reduced the variation of cell numbers in the bacterial inoculum to a minimum. Interchanging the treatment regime between 2 partner teeth after sterilization eliminated the influence of anatomic variation on the treatment outcome. The reuse of teeth after sterilization has been reported in several studies. $22,28,29$

Two different kinds of endodontic experiments were performed. In a first part, $S$. intermedius was subjected to PAD treatment immediately after inoculation of the teeth, whereas in the second part cultures of $S$. intermedius were incubated overnight inside the root canals and treated on the following day. In the first experimental situation, the organisms were still in a planktonic state, because they did not have the time to settle on the canal walls, creep into dentinal tubules, or maybe even form a monospecies biofilm. Care was taken to remove any liquid from the pulp chamber before irradiation. Doing this, only the remainder of the 
suspension within the root canal was subjected to PAD and subsequent paper point sampling. This permitted testing if the amount of noncollimated light that can be delivered through the guiding tip into the root and up to the apical part of the canal is sufficient to achieve a clinically relevant reduction in the bacterial load. A lot of light is lost on the way. Although complete eradication of $3 \times 10^{7}$ organisms $/ \mathrm{mL}$ could be achieved inside the tube lids, a mean $0.3 \%$ of the organisms in the root canals survived $\left(2.51 \log _{10}\right.$ reduction). Still, it could be proved that an effective part of the light, though noncollimated, reaches the inside of the canal, and a reduction of $99.7 \%\left(2.51 \log _{10}\right)$ certainly is a valuable decrease in a clinical situation.

The second experimental setup focussed on bacteria adhering to the canal walls. In a study conducted by Soukos et al., ${ }^{31}$ it could be demonstrated via scanning electron microscopy that the rinsing procedure carried out after endodontic preparation of the teeth $(1 \mathrm{~mL} 17 \%$ EDTA solution for 3 minutes followed by $1 \mathrm{~mL} 6 \%$ $\mathrm{NaOCl}$ solution for 3 minutes) removed the smear layer and left the dentinal tubules open for bacterial penetration. In this part of the experiments, the endodontium was dried carefully before PAD therapy, and the samples gained for microbial evaluation resulted from circumferential filing of the root canal. The mean posttreatment reduction of $95.82 \%\left(1.38 \log _{10}\right)$ showed that the effect of the light is again weaker on adherent organisms than on bacteria in suspension inside the canal lumen, but it also proved that an effective part of the light is able to reach adherent bacteria, and that a significant and clinically relevant decrease of endodontic pathogens infecting the tooth can be achieved.

\section{CONCLUSION}

To our knowledge, this is the first study using a lamp and not a laser for endodontic PAD. It could be proved that noncollimated light can be delivered into prepared root canals, propagate to some extent into dentinal tubules and effectively kill endodontic pathogens within the short application time of 30 seconds. Further studies will determine if the results obtained in the experimental setups described here can be equalled in vivo.

The authors thank Lene Friis for excellent technical support and Alan Richards for providing the teeth used in the experiments.

\section{REFERENCES}

1. de Chevigny C, Dao TT, Basrani BR, Marquis V, Farzaneh M, Abitbol S, et al. Treatment outcome in endodontics: the Toronto study-phase 4: initial treatment. J Endod 2008;34:258-63.

2. Reid RJ, Abbott PV, McNamara JR, Heithersay GS. A five-year study of Hydron root canal fillings. Int Endod J 1992;25:213-20.

3. Weiger R, Rosendahl R, Lost C. Influence of calcium hydrox- ide intracanal dressings on the prognosis of teeth with endodontically induced periapical lesions. Int Endod J 2000; 33:219-26.

4. Dugas NN, Lawrence HP, Teplitsky PE, Pharoah MJ, Friedman S. Periapical health and treatment quality assessment of root-filled teeth in two Canadian populations. Int Endod J 2003;36:181-92.

5. Georgopoulou MK, Spanaki-Voreadi AP, Pantazis N, Kontakiotis EG, Morfis AS. Periapical status and quality of root canal fillings and coronal restorations in a Greek population. Quintessence Int 2008;39:e85-92.

6. Kirkevang LL, Horsted-Bindslev P, Orstavik D, Wenzel A. Frequency and distribution of endodontically treated teeth and apical periodontitis in an urban Danish population. Int Endod J 2001;34:198-205.

7. Segura-Egea JJ, Jimenez-Pinzon A, Poyato-Ferrera M, VelascoOrtega E, Rios-Santos JV. Periapical status and quality of root fillings and coronal restorations in an adult Spanish population. Int Endod J 2004;37:525-30.

8. Sidaravicius B, Aleksejuniene J, Eriksen HM. Endodontic treatment and prevalence of apical periodontitis in an adult population of Vilnius, Lithuania. Endod Dent Traumatol 1999; 15:210-5.

9. Siqueira JF Jr, Rocas IN, Alves FR, Campos LC. Periradicular status related to the quality of coronal restorations and root canal fillings in a Brazilian population. Oral Surg Oral Med Oral Pathol Oral Radiol Endod 2005;100:369-74.

10. Barthel CR, Zimmer S, Trope M. Relationship of radiologic and histologic signs of inflammation in human root-filled teeth. J Endod 2004;30:75-9.

11. Wu MK, Dummer PM, Wesselink PR. Consequences of and strategies to deal with residual post-treatment root canal infection. Int Endod J 2006;39:343-56.

12. Peters OA, Peters CI, Schonenberger K, Barbakow F. ProTaper rotary root canal preparation: effects of canal anatomy on final shape analysed by micro CT. Int Endod J 2003;36:86-92.

13. Wu MK, van der Sluis LW, Wesselink PR. The capability of two hand instrumentation techniques to remove the inner layer of dentine in oval canals. Int Endod J 2003;36:218-24.

14. Siqueira JF Jr, Magalhaes KM, Rocas IN. Bacterial reduction in infected root canals treated with $2.5 \% \mathrm{NaOCl}$ as an irrigant and calcium hydroxide/camphorated paramonochlorophenol paste as an intracanal dressing. J Endod 2007;33:667-72.

15. Siqueira JF Jr, Rocas IN, Paiva SS, Guimaraes-Pinto T, Magalhaes KM, Lima KC. Bacteriologic investigation of the effects of sodium hypochlorite and chlorhexidine during the endodontic treatment of teeth with apical periodontitis. Oral Surg Oral Med Oral Pathol Oral Radiol Endod 2007;104:122-30.

16. Waltimo T, Trope M, Haapasalo M, Orstavik D. Clinical efficacy of treatment procedures in endodontic infection control and one year follow-up of periapical healing. J Endod 2005;31:863-6.

17. Peters LB, Wesselink PR, Buijs JF, van Winkelhoff AJ. Viable bacteria in root dentinal tubules of teeth with apical periodontitis. J Endod 2001;27:76-81.

18. Sen BH, Piskin B, Demirci T. Observation of bacteria and fungi in infected root canals and dentinal tubules by SEM. Endod Dent Traumatol 1995;11:6-9.

19. Chavez de Paz LE. Redefining the persistent infection in root canals: possible role of biofilm communities. J Endod 2007;33:652-62.

20. Fabricius L, Dahlen G, Sundqvist G, Happonen RP, Moller AJ. Influence of residual bacteria on periapical tissue healing after chemomechanical treatment and root filling of experimentally infected monkey teeth. Eur J Oral Sci 2006;114:278-85.

21. Sjogren U, Figdor D, Persson S, Sundqvist G. Influence of infection at the time of root filling on the outcome of endodontic 
treatment of teeth with apical periodontitis. Int Endod J 1997; 30:297-306

22. Bergmans L, Moisiadis P, Huybrechts B, Van Meerbeek B, Quirynen M, Lambrechts P. Effect of photo-activated disinfection on endodontic pathogens ex vivo. Int Endod J 2008;41:227-39.

23. Bonsor SJ, Nichol R, Reid TM, Pearson GJ. An alternative regimen for root canal disinfection. Br Dent J 2006;201:101-5, discussion 98.

24. Fimple JL, Fontana CR, Foschi F, Ruggiero K, Song X, Pagonis TC, et al. Photodynamic treatment of endodontic polymicrobial infection in vitro. J Endod 2008:34:728-34.

25. Fonseca MB, Junior PO, Pallota RC, Filho HF, Denardin OV, Rapoport A, et al. Photodynamic therapy for root canals infected with Enterococcus faecalis. Photomed Laser Surg 2008;26:209-13.

26. Foschi F, Fontana CR, Ruggiero K, Riahi R, Vera A, Doukas AG, et al. Photodynamic inactivation of Enterococcus faecalis in dental root canals in vitro. Lasers Surg Med 2007;39:782-7.

27. Garcez AS, Nunez SC, Hamblin MR, Ribeiro MS. Antimicrobial effects of photodynamic therapy on patients with necrotic pulps and periapical lesion. J Endod 2008;34:138-42.

28. Garcez AS, Ribeiro MS, Tegos GP, Nunez SC, Jorge AO, Hamblin MR. Antimicrobial photodynamic therapy combined with conventional endodontic treatment to eliminate root canal biofilm infection. Lasers Surg Med 2007;39:59-66.

29. Seal GJ, Ng YL, Spratt D, Bhatti M, Gulabivala K. An in vitro comparison of the bactericidal efficacy of lethal photosensitization or sodium hyphochlorite irrigation on Streptococcus intermedius biofilms in root canals. Int Endod J 2002;35:268-74.

30. Silva Garcez A, Nunez SC, Lage-Marques JL, Jorge AO, Ribeiro MS. Efficiency of $\mathrm{NaOCl}$ and laser-assisted photosensitization on the reduction of Enterococcus faecalis in vitro. Oral Surg Oral Med Oral Pathol Oral Radiol Endod 2006;102:e93-8.

31. Soukos NS, Chen PS, Morris JT, Ruggiero K, Abernethy AD, Som S, et al. Photodynamic therapy for endodontic disinfection. J Endod 2006;32:979-84.

32. Williams JA, Pearson GJ, Colles MJ. Antibacterial action of photoactivated disinfection (PAD) used on endodontic bacteria in planktonic suspension and in artificial and human root canals. J Dent 2006;34:363-71.

33. Bahcall J, Howard P, Miserendino L, Walia H. Preliminary investigation of the histological effects of laser endodontic treatment on the periradicular tissues in dogs. J Endod 1992;18:47-51.

34. Ramskold LO, Fong CD, Stromberg T. Thermal effects and antibacterial properties of energy levels required to sterilize stained root canals with an Nd:YAG laser. J Endod 1997;23:96-100.

35. Wetter NU, Walverde D, Kato IT, Eduardo Cde P. Bleaching efficacy of whitening agents activated by xenon lamp and 960-nm diode radiation. Photomed Laser Surg 2004;22:489-93.

36. Zhang C, Wang X, Kinoshita J, Zhao B, Toko T, Kimura Y, et al. Effects of KTP laser irradiation, diode laser, and LED on tooth bleaching: a comparative study. Photomed Laser Surg 2007;25:91-5.

37. Calzavara-Pinton PG, Venturini M, Capezzera R, Sala R,
Zane C. Photodynamic therapy of interdigital mycoses of the feet with topical application of 5-aminolevulinic acid. Photodermatol Photoimmunol Photomed 2004;20:144-7.

38. Horfelt C, Funk J, Frohm-Nilsson M, Wiegleb Edstrom D, Wennberg AM. Topical methyl aminolaevulinate photodynamic therapy for treatment of facial acne vulgaris: results of a randomized, controlled study. Br J Dermatol 2006;155:608-13.

39. Matevski D, Weersink R, Tenenbaum HC, Wilson B, Ellen RP, Lepine G. Lethal photosensitization of periodontal pathogens by a red-filtered xenon lamp in vitro. J Periodontal Res 2003;38:428-35.

40. Hunt DE, Jones JV, Dowell VR Jr. Selective medium for the isolation of Bacteroides gingivalis. J Clin Microbiol 1986;23:441-5.

41. Jensen SB, Loe H, Schiott CR, Theliade E. Experimental gingivitis in man. 4. Vancomycin induced changes in bacterial plaque composition as related to development of gingival inflammation. J Periodontal Res 1968;3:284-93.

42. Schneider SW. A comparison of canal preparations in straight and curved root canals. Oral Surg Oral Med Oral Pathol Oral Radiol Endod 1971;32:271-5.

43. StataCorp. Stata statistical software: release 10. College Station (TX): StataCorp; 2007.

44. Cogulu D, Uzel A, Oncag O, Eronat C. PCR-based identification of selected pathogens associated with endodontic infections in deciduous and permanent teeth. Oral Surg Oral Med Oral Pathol Oral Radiol Endod 2008;106:443-9.

45. Pinheiro ET, Gomes BP, Ferraz CC, Sousa EL, Teixeira FB, Souza-Filho FJ. Microorganisms from canals of root-filled teeth with periapical lesions. Int Endod J 2003;36:1-11.

46. Sedgley C, Nagel A, Dahlen G, Reit C, Molander A. Real-time quantitative polymerase chain reaction and culture analyses of Enterococcus faecalis in root canals. J Endod 2006;32:173-7.

47. Vigil GV, Wayman BE, Dazey SE, Fowler CB, Bradley DV Jr. Identification and antibiotic sensitivity of bacteria isolated from periapical lesions. J Endod 1997;23:110-4.

48. Waltimo TM, Siren EK, Torkko HL, Olsen I, Haapasalo MP. Fungi in therapy-resistant apical periodontitis. Int Endod J 1997;30:96-101.

49. Demidova TN, Hamblin MR. Effect of cell-photosensitizer binding and cell density on microbial photoinactivation. Antimicrob Agents Chemother 2005;49:2329-35.

50. Saunders EM, Saunders WP. The challenge of preparing the curved root canal. Dent Update 1997;24:241-4, 6-7.

\section{Reprint requests:}

Sebastian Schlafer

School of Dentistry

Faculty of Health Sciences

Aarhus University

Vennelyst Boulevard 9

8000 Aarhus

Denmark

sebastian.schlafer@hotmail.de 